\title{
Why Organic Farming Should Embrace Co-Existence with Cisgenic Late Blight-Resistant Potato
}

\author{
Godelieve Gheysen ${ }^{1, *}$ and René Custers ${ }^{2}$ \\ 1 Faculty of Bioscience Engineering, Department of Molecular Biotechnology, Ghent University, \\ Coupure Links 653, 9000 Ghent, Belgium \\ 2 VIB, Rijvisschestraat 120, 9052 Ghent, Belgium; rene.custers@vib.be \\ * Correspondence: godelieve.gheysen@ugent.be; Tel.: +32-9-264-5888
}

Academic Editor: Gerhart U. Ryffel

Received: 20 July 2016; Accepted: 18 January 2017; Published: 25 January 2017

\begin{abstract}
The EU regulation on organic farming does not allow the use of genetically modified organisms (GMOs) which are subject to Directive 2001/18/EC. Mutagenesis using irradiation or chemicals is genetic modification, but the organisms obtained through these techniques are not subject to the provisions of the GMO directive. Such mutants can therefore be used in organic agriculture. Derived from its basic principles, organic farming can only use natural substances to control disease and crops should be resilient, which, in the case of disease resistance, means that durable (horizontal) resistance is preferred to vertical (single gene) resistance. Cisgenesis can achieve such a durable resistance by introducing multiple resistance genes in one step. These multiple-resistant plants only contain natural genes that can also be introduced by breeding. In case cisgenic plants are not subject to the provisions of the GMO legislation, they can even be legally used in organic agriculture. In case they are not exempted from the GMO regulation, the question is: why obstruct a cisgenic potato crop that can hardly be distinguished from a potato crop that is the result of conventional breeding? Among the reasons why organic agriculture does not allow the use of GMOs it is mentioned that genetic engineering is unpredictable, it causes genome disruption and it is unnatural. However, our knowledge of plant genome evolution and breeding has increased dramatically. We now know that breeding is more unpredictable and causes more genome disruption than genetic engineering. Recent field trials have shown the efficacy of cisgenic late blight-resistant potatoes carrying multiple resistance genes. Large-scale growing of such durably resistant potatoes would not only be environmentally beneficial by it would strongly reducing the need for fungicide sprays in conventional potato cultivation and it would also reduce the disease pressure in organic potato cultivation.
\end{abstract}

Keywords: cisgenesis; late blight resistance; new breeding technologies; organic farming

\section{Introduction}

The ideology and methods of organic farming started as different movements in many places that have been united in the International Federation of Organic Movements (IFOAM). Plenty of information on organic farming can be found on their website [1]. The principles of organic agriculture are based on health, ecology, fairness and care. Therefore, organic agriculture should:

(1) sustain and enhance the health of soil, plant, animal, human and planet as one and indivisible.

(2) be based on living ecological systems and cycles, work with them, emulate them and help sustain them.

(3) build on relationships that ensure fairness with regard to the common environment and life opportunities. 
(4) be managed in a precautionary and responsible manner to protect the health and well-being of current and future generations and the environment.

A more detailed description of the principles can also be found on the FAO website [2].

IFOAM notes that "Genetic engineering focuses on the genetic makeup without taking into account the complete organism or system in which the organism functions. It is thus a contradiction to the above mentioned principle aims of organic agriculture." This general principle on the exclusion of GMOs has been implemented in much legislation. For instance, the EU regulation on organic farming does not allow the use of genetically modified organisms (GMOs) which are subject to Directive 2001/18/EC [3]. Annex IB of this GMO directive defines mutagenesis using irradiation or chemicals as a technique of genetic modification, but through article 3 of this directive the organisms obtained through these techniques are not subject to the provisions of that GMO directive. Such mutants can therefore be used in organic agriculture. The effects of the principles of organic farming towards GMOs do not only prevent the use of GMOs in organic agriculture itself, but they also play an important role in protests against the use of GMOs in conventional agriculture.

Whether cisgenic plants should be outside the scope of the GMO legislation and allowed to be used in organic agriculture was already discussed in detail 10 years ago [4-9]. We believe it is time to reconsider this issue in the light of new insights on genomic dynamics during breeding and evolution obtained from the many genome sequencing data from the past decade [10-14].

\section{Durable and Ecological Control of Late Blight}

The most devastating disease in potato (Solanum tuberosum) cultivation throughout the world is late blight caused by Phytophthora infestans, a fungus-like micro-organism from the class of oomycetes. Late blight problems result in economic costs of up to 9.4 billion dollars annually [15]. A large part of these costs is associated with yield losses in developing countries and the purchase and application of fungicides in developed regions. Farmers in humid, moderate climates spray, on average, 10 to 15 times to control the disease, but this can go up to 20 times in wet growing seasons [16]. Organic potato producers must rely on Organic Materials Review Institute-listed products [17], labeled for the control of late blight, such as copper or sulfur products and selected biological fungicides. Alternatively they can choose to grow very early varieties that can be harvested before late blight exerts its most damaging effects.

A more ecological way of controlling late blight is the use of resistant varieties. Many wild tuber-bearing potato species (belonging to different species of the genus Solanum) contain resistance genes which encode proteins that recognize effectors from the late blight pathogen and evoke a hypersensitive response to block the infection [18]. Late blight resistance (LBR) genes have been transferred from wild species into commercial potato varieties through conventional breeding. This process is complicated due to differences in ploidy and the inability of certain potato species to directly cross-hybridize and it is time-consuming because of the many backcrosses needed to develop a variety suitable for commercial use [18].

One decade ago, two resistant cultivars were released that have since been used in organic potato production in Belgium and the Netherlands. For instance, the cultivar Bionica contains the Rpi-blb2 resistance gene from S. bulbocastanum. Cultivated potato, Solanum tuberosum, cannot be crossed directly to $S$. bulbocastanum. A complicated interspecific bridge crossing scheme was needed to introgress this Rpi-blb2 resistance into potato [18]. Besides crossing the species barriers, this breeding trajectory also involved the use of the chemical colchicine, a mitotic drug, to double the number of chromosomes. Obviously, after mixing the genetic material of potato with that of three wild species, many backcrosses to potato were needed to remove all the unwanted characteristics of these wild species. In the case of Bionica, this whole process took more than 40 years of dedicated breeding.

The big drawback of introducing single LBR genes by breeding is that the 10-40 years needed to obtain a good resistant variety are often overthrown in a few years due to mutations in the pathogen which result in the loss of recognition, causing the resistance to lose its efficacy. Phytophthora 
produces vast amounts of spores and is capable of producing 20 generations per growing season. The combination of a group of different LBR genes is a better strategy to protect the potato against Phytophthora infection, but this is very difficult to achieve using conventional breeding.

Derived from the basic principles of organic agriculture, which state that farmers should only use natural substances for disease control or, even better, crops should be resilient, this means, in the case of disease resistance, that durable (multigene) resistance is preferred to vertical (single gene) resistance.

\section{Cisgenic Late Blight Resistance}

Cisgenesis can achieve such a durable resistance by introducing multiple resistance genes in one step with the additional advantage that important variety properties will be conserved.

Cisgenesis can be defined as genetic modification with cisgenes only [19] whereby "a cisgene is a natural gene, coding for an (agricultural) trait, from the crop plant itself or from a sexually compatible donor plant that can be used in conventional breeding. The gene belongs to the conventional breeder's gene pool." This definition clearly states that cisgenesis is not limited to genes from the same species, for instance S. bulbocastanum genes belong to the same breeder's gene pool as $S$. tuberosum as exemplified by the example of the late blight-resistant Bionica. In the cisgenic approach, plants receive genes by genetic engineering but, in contrast to transgenesis, these genes come only from crossable species and are under control of their natural regulatory elements and are used in their natural orientation [4]. Furthermore, foreign genetic material, such as selectable marker genes, is absent.

In recent years various LBR genes that recognize different effectors have been isolated and characterized [20]. At Wageningen University \& Research Center, this was the focus of the DuRPh (Durable Resistance against Phytophthora) program that ran from 2006 until 2015. A number of these genes have been introduced in different combinations by genetic engineering into the potato variety Desirée [21]. It is indeed possible to join several resistance genes from different wild potato species into one cassette, allowing, in a single step, the transfer of several genes into a commercial potato variety while maintaining the original variety characteristics.

To assess the quality of the resistance in the genetically engineered potatoes, field trials were performed in The Netherlands over many years and in Belgium in 2011 and 2012 [16]. The Desirée potatoes in those trials contained individual or multiple LBR genes from Solanum bulbocastanum, S. stoloniferum and S. venturii. The results of those field trials showed that stacking of multiple genes is both functional and necessary to obtain good resistance against late blight. It is estimated that using a combination of three or four different LBR genes can reduce fungicide use by at least $80 \%$. Some applications of fungicide are estimated to remain necessary as part of a responsible resistance management strategy.

\section{Cisgenesis Is Very Similar to Breeding, the Main Differences Being Its Precision and Swiftness}

Cisgenesis employs genetic engineering and allows for the rapid transfer of useful genes from wild relatives into domesticated crops. Cisgenesis is very similar to breeding as, in both cases, only genes from the sexually compatible gene pool of the recipient plant are introduced. The European Food Safety Authority (EFSA) Panel on Genetically Modified Organisms concluded that similar hazards can be associated with cisgenic and conventionally bred plants [22]. In case of cisgenesis, only the selected genes are introduced into the cultivar, without unwanted genes for toxicity or other undesirable traits such as bad taste. Because of this, cisgenesis can even be considered safer than conventional breeding. For instance, the potato variety Lenape, obtained from a cross between S. chacoense and S. tuberosum, caused illness because it contained high levels of toxic glycoalkaloids similar to $S$. chacoense [23].

Genetic engineering furthermore allows the easy combination of several resistance genes from different wild relatives into one variety, enabling a more durable resistance to be obtained in one transformation step. With respect to the organic farming principles, cisgenic potatoes with multiple resistance to late blight are a much better choice than resistant potatoes with single resistance genes introgressed by breeding. Cisgenesis is better not only because of its more durable resistance, but also 
because the variety that is at the basis of the cisgenic event has a history of safe use, whereas the resistant new variety obtained through conventional breeding still has to prove its safety. In the optimal scenario, different varieties with different combinations of LBR genes should either be alternated in time and space or used as so-called mixed varieties to ensure a durable resistance [15].

Let us compare a cisgenic potato with a multiple LBR to Bionica which is being cultivated by organic farmers. Both contain similar genes from wild Solanum relatives (species different from Solanum tuberosum). They are both immune to infection, which enables organic farmers to avoid copper fungicides (still allowed in organic agriculture in several countries) and keeps them from harvesting their potatoes early, contributing to higher yields and more sustainable cultivation. The cisgenic multiple LBR has the advantage that it is more durable than the resistance in Bionica. During the breeding process of Bionica, selection might have included looking for additional useful characteristics but, due to linkage drag, it has also resulted in less desirable characteristics such as lower palatability and inferior processing qualities. Cisgenesis can be performed on a cultivar with desirable agronomic, eating and processing characteristics and will only add disease resistance.

So why would organic agriculture accept Bionica and oppose the cultivation of a cisgenic LBR variety? To answer this question we will first discuss the legal status of cisgenic LBR potatoes and then confront the organic principles with our current knowledge about such potatoes.

\section{Can Cisgenic LBR Potatoes Not Be a GMO?}

Despite the fact that the EFSA Panel on Genetically Modified Organisms concluded that similar hazards can be associated with cisgenic and conventionally bred plants, their conclusion is that the same GMO legislations and procedures can be applied towards transgenic and cisgenic organisms [22]. It remains to be decided if current regulatory discussions will consider that cisgenic plants are not subject to the requirements of the GMO legislation because the same gene combination could, in principle, also be obtained by conventional breeding. Treating cisgenic plants in the same way as plants obtained by conventional breeding would take away the regulatory burden and the GMO stigma. This would allow the use of cisgenic plants in organic agriculture in the same way as mutant plants which are exempted from the GMO legislation.

For determining whether or not a cisgenic crop would be subject to the GMO legislation, it should first be recognized that this legislation in most jurisdictions in the world contains both process- and product-related criteria. This is the most apparent in the definitions part of the Cartagena protocol on Biosafety, but also holds true for the European GMO legislation [3]. The consequence of this is that even though a certain technology may trigger the legislation, whether the organisms obtained through them are covered by this legislation is dependent on the question of whether the organism contains a "novel combination of genetic material", that is a genetic combination beyond what is possible through mating and natural recombination. As the same combination of resistance genes in the potato genome can, in principle, be obtained by conventional breeding, the cisgenic potatoes do not have a novel combination compared to conventionally bred potatoes, and therefore would not be subject to the European GMO legislation.

In the US one of the regulatory triggers used by USDA-APHIS is the involvement of a plant pest [24]. The use of disarmed Agrobacterium tumefaciens has always been considered to constitute such a regulatory trigger, even though the disarmed bacterium is no longer able to cause disease. The introduction of cisgenes using particle bombardment does not trigger this legislation, leading to the conclusion that some cisgenic crops are, but others are not, covered by it. The regulatory trigger used by the EPA in the US is the incorporation of so-called 'Plant-Incorporated Protectants' (PIPs) [25]. Apparently, genes that are introduced to produce resistance factors are considered PIPs irrespective of whether such genes already exist in the natural gene pool. This does not seem to be very logical and also here leads to the conclusion that some cisgenic organisms are covered and others are not. The recent review performed by the US regulatory authorities has not led to a fundamental change to 
this situation. It is clear that on the basis of what we have presented above, regulatory requirements for cisgenic LBR potatoes, if any, should be very limited.

\section{What If Cisgenic LBR Potatoes Are Considered a GMO?}

Cisgenic potatoes are the product of genetic engineering. Agrobacterium tumefaciens is being used to introduce the LBR genes, thereby triggering the need for deregulation by USDA-APHIS [24]. So far, such cisgenic potatoes are also considered to trigger the European GMO legislation, and as a consequence, a battery of safety testing, a market authorization, and labeling of the potatoes and derived food and feed are required [3].

The regulatory cost for commercialization of a GMO is estimated to be US\$ 1 to 15 million, limiting the use of this technology to large multinationals with deep pockets and the most valuable crops [26,27]. In case cisgenic potatoes are subject to the requirements of the GMO legislation, these high costs will impede their commercialization. In addition, although highly desirable from a resistance management viewpoint, it is very unlikely that several different varieties with various combinations of resistance genes will make it to the market, as each individual transformation event needs to go through the whole costly regulatory process again.

The question, however, is whether such cisgenic potatoes require a lot of safety testing and regulatory oversight as they do not differ in a meaningful way from LBR potatoes developed using conventional breeding. The only differences are the presence of T-DNA border base pairs and the chromosomal location of the LBR genes. T-DNA sequences have been proven to naturally occur in tobacco and sweet potato $[14,28]$ and it is known that the chromosomal location of genes can naturally change following gene duplication events or transposon activity. Additionally, in this particular case, the LBR genes belong to a category of general resistance genes (the NBS-LRR genes) of which potato already possesses a few hundred variants which are dispersed all over the genome [20].

T-DNA border sequences are only present when Agrobacterium tumefaciens has been used to introduce the cisgenes. However, also, in that case, the number of additional nucleotides that has been introduced is limited to three base pairs from the left T-DNA border and 21 base pairs from the right T-DNA border. In fact, in many cases, the number of base pairs introduced is even lower, with fewer or no T-DNA sequences introduced from the right border, and sometimes also the base pairs from the left T-DNA border are missing [29]. In practice it is often possible to select cisgenic events that contain no T-DNA sequences, resulting in a plant that only differs from the conventional plant in its location of the cisgene. However, this latter artefact can be circumvented today by means of introducing cisgenes using modern genome editing technology.

A key difference between the EU and US legislation of GM crops is that the US employs deregulation declaring the new crop as safe as existing crops after thorough evaluation, with no need for further actions $[3,30]$. Recently a bill was passed in the US under which standards for the voluntary bioengineering status disclosure will be developed [31]. In the EU, GM crops can get an authorization after being declared as safe as the conventional counterpart. This authorization (that is limited in time to 10 years) implies further administrative burdens because of obligatory monitoring and labeling, the latter triggering in turn coexistence measures and segregation of GM products. Although the label was created to allow consumer choice between GM or non-GM products, both safe to eat, it has become a stigma. Non-GMO is being used as a marketing tool, sometimes even when genetic engineering is not at stake. An absurd example of the latter is the non-GMO salt that is being advertised on the Amazon website [32]. To avoid negative effects on their image and sales, almost all companies in the EU avoid using GM in their food products, resulting in the absence of choice for consumers. However, GM products are abundantly present in animal feed in the EU.

The question is, again, why LBR potatoes need to be monitored, segregated and labeled only if obtained by cisgenesis and not if obtained by interspecific breeding. This inconsistency in the different regulation of plants with the same properties has also been disputed by scientific organizations and government expert panels [33,34]. 
Nevertheless, in case cisgenic LBR potatoes do constitute an organism subject to the GMO legislation, they cannot legally be cultivated by organic farmers. This is a pity as they would significantly expand the tools that organic farmers currently have access to and LBR plants would reduce the burden of copper fungicides on soil health. Copper has accumulated to toxic levels in some soils, and for that reason, the EU has limited application to $6 \mathrm{~kg} / \mathrm{ha}$ annually, while Scandinavian countries banned the use of copper in agriculture completely.

\section{The Compatibility of Innovative Breeding Technologies with Organic Farming}

So far we have focused on the product characteristics of the cisgenic LBR potato to discuss its potential for acceptance in organic farming. However, the organic movement also uses intrinsic, ethical arguments related to the process of genetic engineering to ban GMOs [35]. The concept of intrinsic value and integrity of plants is very important in this respect, and criteria have been developed for evaluating potential integrity infringements during breeding or cultivation [36].

From a biocentric perspective, four levels of integrity can be distinguished [36] which we very briefly describe here:

(1) Integrity of life: organisms maintain themselves through self-regulating activities, and, for example, applying synthetic inputs interferes with this capacity.

(2) Plant-specific integrity: plants need to live in optimal association with micro-organisms, and in vitro or hydroponic culture conditions do not comply with this principle.

(3) Genotypic integrity: can be defined as the wholeness and completeness of the species-specific genome; transgenesis which breaks reproductive barriers violates this integrity.

(4) Phenotypic integrity: is the state of wholeness or completeness of an individual plant or crop, and reducing the plant to its cellular potential by tissue culture impairs plant worthiness.

Lammerts van Bueren et al. [36] added to the description of these criteria that techniques of embryo rescue, colchicine-induced chromosome doubling and chemically induced mutations violate several integrity levels of plants.

The intrinsic value of nature and the diversity of its living organisms is undisputable, and therefore we respect a philosophy that wants to help to protect that. On the other hand, we must also admit that most of the crops we grow have been domesticated to such an extent that their naturalness can be challenged. Human intervention has had a profound impact on their characteristics, and in many crops, we exploit odd mutational phenotypes that would never exist and survive in nature. The different crop varieties of the Brassica family are telling examples [37]. So even in a biocentric view, human intervention plays an important role. The major question indeed is how much human intervention is allowed and to what extent can technology be used to still be in line with the organic principles.

Human intervention in crops has had the result that many crops have lost quite some of the resilience and nutritional qualities that wild plants possess during domestication [38,39]. For organic farming, resilience is extremely important and that is why many breeding activities have the goal of bringing back some of that resilience. Cisgenesis could be one approach to bring back some of that resilience in a faster and more direct manner. The major question is whether cisgenesis remains unacceptable for organic farming in a context where other technologies that are necessary to transfer genes from wild species to crop cultivars, such as induced chromosome doubling, are tolerated.

Among the reasons that organic agriculture does not allow the use of GMOs the following are mentioned: genetic engineering is unnatural because, it breaks through species barriers, it causes genome disruption and usually has a tissue culture step, and it violates integrity criteria as listed above.

In contrast to general beliefs there is nothing unnatural about crossing species barriers. It is rare but it occurs in nature, as testified by many examples found in genome sequences. Insects and nematodes have acquired genes from bacteria and fungi [40], and similar DNA transfers have been found in plants. Also, in the animal kingdom, DNA transfers are known and about $6 \%$ of the human genome is of viral origin. The most amazing example in the plant world is the recent discovery 
that sweet potato is a naturally transgenic plant that received DNA from Agrobacterium at least 10,000 years ago [14]. Also breeding is able to cross species borders to some extent, and even borders between genera are not always irrefrangible, modern wheat breeding being a nice illustration of that [41]. Furthermore, the cisgenic LBR potatoes do not violate the reproductive barriers as these potatoes only contain sequences from crossable related species.

Initially there was uncertainty about the long-term safety of GMOs, as more than 30 years ago not much was known on the transformation process and its potential consequences, such as unintended side effects. Some argue that the insertion of cisgenes in a random genomic position leads to "genomic disruption" and, consequently, unpredictable side effects. However, genomic disruption is a natural process that occurs as a result of transposon activity and natural DNA duplication or rearrangements of DNA sequences during conventional breeding and evolution [19]. Our knowledge of plant transformation, plant genome evolution and breeding has increased dramatically in the past decades. We now know that breeding and mutagenesis are more unpredictable and cause more genome disruption than genetic engineering [10-13]. For instance, the comparison of genomic variation in transgenic plants to the genomic variation observed in cultivars and mutagenized lines revealed that, on average, the number of genes affected by structural variations in transgenics was one order of magnitude lower than that of fast neutron mutants and two orders of magnitude lower than between cultivars [10]. The authors concluded that genetic engineering rarely results in novel genetic variation and these rare events are analogous to spontaneous genetic variants present in the germplasm, or to induced mutations.

Finally, there is still the concern of tissue culture. Most transformation protocols indeed have a tissue culture step to regenerate the transformed shoots. Nevertheless, outside of genetic engineering, tissue culture is also a common technique for the propagation of plants and a very useful method to obtain virus-free plantlets. It has also been used in breeding programs to rescue embryos from interspecific or intergeneric crosses. Many of the cultivars currently used, also in organic agriculture, originate from breeding where, in the past these techniques have been implemented. Furthermore, cultivars developed from mutagenized plants are also non-labeled and being used in organic agriculture.

Lammerts van Bueren et al. [35] have therefore suggested the development of an organic certification system to catalogue varieties that comply with the standards of IFOAM, resulting in a "green" list of varieties that are allowed in organic agriculture. An important question is how many crosses one should go back to assess whether undesired techniques were applied during the breeding process. The LBR variety Bionica which is recommended for organic farming [42] was indeed developed using chromosome doubling colchicine treatment.

In the US, the National Organic Program (NOP) [43] requires the use of certified organic seeds of crop cultivars. However, when the NOP was formalized, it was realized that not many cultivars were available as certified organic seeds and, therefore, an exception was created that allowed a grower to purchase and use conventional, untreated seeds. Nevertheless, this is a temporary measure given the current limitations, and in the long term, the organic community wants to pursue the goals initially set with regard to appropriate technologies and seed sources.

\section{Could Organic Farming Decide on GM Case by Case?}

The first genetically modified plants are 30 years old and contain antibiotic resistance and herbicide resistance genes derived from bacteria. It is rather obvious why organic farming, which is very strict on the use of antibiotics and prohibits the use of synthetic herbicides, decided to ban these GMOs. However, genetic modification today has a much broader spectrum than the original transgenics. Cisgenesis is genetic modification using only genes from the sexually compatible gene pool. It is very difficult to distinguish cisgenic plants from plants obtained by conventional breeding.

The difficulty of distinguishing between engineered plants and conventional plants becomes even bigger with the arrival of genome-edited plants. In recent years, several methods have been developed 
with which one can introduce, in a very precise manner, a desired DNA change in any chosen genomic location. One method uses synthetic DNA oligonucleotides to introduce a specific point mutation in the gene of interest ('oligo-directed mutagenesis' (ODM)). Another group of techniques makes use of nucleases that generate breaks in the DNA at the desired location in the genome ('site-directed nucleases' (SDN)), which are then repaired by the cells' own repair mechanism. During that repair, often a few base pairs are eaten away or a few are added, leading to disruption of the gene. The technology can also be used to direct specific changes. The most widely employed SDN technology uses the CRISPR/Cas9 system [44]. When these technologies are used to introduce small directed mutations, the plants that are made cannot be distinguished from plants that have resulted from natural phenomena or conventional breeding techniques.

The modern genome editing techniques can also be used to introduce LBR into cultivated potato. Both the ODM and SDN technologies can, for instance, be used to edit particular potato genes-which are called S-genes (susceptibility genes) —in such a way that the pathogen can no longer multiply [45]. The biotechnology company Cibus based in San Diego, California, is working on LBR in potato using ODM, and in other places in the world the SDN technology is being explored for the same purpose. The combined use of Rpi-genes, S-genes and other genes that contribute to horizontal resistance would make the Phytophthora resistance even more durable and would contribute to the development of potatoes that show true resilience.

If one cannot distinguish between a potato crop that is the result of natural phenomena, the result of conventional breeding, or the result of modern technological intervention, why then obstruct the use of the latter category in agriculture? As already elaborated above, we believe that it is not the mere use of technology that is contrary to the philosophy of organic agriculture, as certain types of technologies, such as chromosome doubling, the use of genetic markers, and mutagenesis, are, to some extent, tolerated. Is it not possible to discuss more modern technological approaches and their possible value in achieving the organic agriculture goals? Urs Niggli, the director of the Swiss-based research institute for organic agriculture FiBL, is one of the people who apparently is of the opinion that it should be possible to discuss this [46]. When he spoke out on the issue on 6 April 2016 in the German newspaper Tageszeitung, this created a storm of negative reactions from within the organic sector, stating that he was doing a big favor to the GMO industry. Genome-edited crops for sure are developed using modern technology, but on the issue of whether they, in fact, are organisms that are subject to the provisions of the GMO legislation, the jury is still out.

Considering the spectrum of breeding technologies that is available to introduce disease resistances into crops, we can conclude that there is a continuum from classical breeding to true transgenesis. The various technologies differ in their grade of invasiveness and their ability to alter genomes beyond what is possible through mating and natural recombination. The most modern technologies, in particular genome editing, are less invasive than transgenesis, and result in alterations that are not beyond what nature can achieve. Cisgenic crops present in that spectrum a type of genetic alteration that does not intend to change the genome of the crop other than introducing a natural gene that already exists in the breeder's gene pool.

We understand that the organic movement cannot ignore their intrinsic, ethical arguments related to the process of genetic engineering and therefore wants to exclude cisgenic LBR potatoes from organic farming. However, based on the arguments concerning cisgenic LBR potatoes given above, we invite them to reconsider their opposition to the use of these potatoes in conventional agriculture. Large-scale cultivation of durably late blight-resistant potatoes would not only be environmentally beneficial by reducing the need for fungicide sprays in conventional potato cultivation, but would also reduce the general disease pressure. This would have significant beneficial spill-over effects in organic potato cultivation by contributing to the prevention of yield losses and by reducing the need for copper-based or other organic fungicides. 


\section{Conclusions}

The GMO legislation and the exclusion of GMOs from organic farming was established at a time that molecular insights in plant genomes were limited. In the last decade this has changed dramatically. High-throughput sequence analysis has revealed that extensive DNA changes occur during breeding and that some plants such as sweet potato and tobacco naturally have T-DNAs from Agrobacterium. With this new knowledge it is vital to reconsider the way we look at modern technology and adjust our views on the basis of the evolving science. Novel crop varieties should be subject to a case-by-case risk assessment independent of the method used for their development as there is no scientific basis for making a distinction between conventional breeding versus more modern techniques to create additional genetic variation. Many current and future GM plants can also not be distinguished from plants obtained by traditional breeding methods. Acceptance of plants resulting from these modern techniques in organic agriculture will probably be a bridge too far. However, in cases where the end product does not differ in a meaningful way from what can be achieved using traditional breeding methods, opposition by the organic movement to their use in conventional agriculture is difficult to understand, especially in those cases where they could help achieve true resilience in plants and help farmers to obtain a good healthy harvest without chemicals and maintaining a healthy soil, in line with many of the principles of organic farming.

Acknowledgments: We are grateful to Ghent University, VIB and ILVO (Institute for Agriculture and Fisheries Research) for their support in the research and development of durable resistance to late blight in potato.

Author Contributions: Godelieve Gheysen and René Custers have jointly developed the basic ideas and have equally contributed to the writing of this paper.

Conflicts of Interest: The authors declare no conflict of interest.

\section{References}

1. Cultivating Change. Available online: www.ifoam.bio (accessed on 24 June 2016).

2. Defining Organic Agriculture. Available online: http://www.fao.org/docrep/003/ac116e/ac116e02.htm (accessed on 24 June 2016).

3. European Union. Directive 2001/18/EC of the European Parliament and of the Council of 12 March 2001 on the deliberate release into the environment of genetically modified organisms and repealing Council Directive 90/220/EEC. Off. J. Eur. Union 2001, 106, 1-38.

4. Schouten, H.J.; Krens, F.A.; Jacobsen, E. Cisgenic plants are similar to traditionally bred plants-International regulations for genetically modified organisms should be altered to exempt cisgenesis. EMBO Rep. 2006, 7, 750-753. [CrossRef] [PubMed]

5. Schouten, H.J.; Krens, F.A.; Jacobsen, E. Do cisgenic plants warrant less stringent oversight? Nat. Biotechnol. 2006. [CrossRef] [PubMed]

6. Giddings, L.V. 'Cisgenic' as a product designation. Nat. Biotechnol. 2006. [CrossRef]

7. Schubert, D.; Williams, D. 'Cisgenic' as a product designation. Nat. Biotechnol. 2006, 24, 1327-1329. [CrossRef] [PubMed]

8. Buning, T.D.C.; van Bueren, E.T.L.; Haring, M.A.; de Vriend, H.C.; Struik, P.C. 'Cisgenic' as a product designation. Nat. Biotechnol. 2006, 24, 1329-1331. [CrossRef] [PubMed]

9. Schouten, H.J.; Krens, F.A.; Jacobsen, E. Reply to 'Cisgenic' as a product designation. Nat. Biotechnol. 2006, 24, 1331-1333.

10. Anderson, J.E.; Michno, J.-M.; Kono, T.J.Y.; Stec, A.O.; Campbell, B.W.; Curtin, S.J.; Stupar, R.M. Genomic variation and DNA repair associated with soybean transgenesis: A comparison to cultivars and mutagenized plants. BMC Biotechnol. 2016. [CrossRef] [PubMed]

11. Schouten, H.J.; Schijlen, E.; Schaart, J.; van de Geest, H.; Papadimitriou, S.; Smulders, M.J.M.; Finkers, R.; Sanchez Perez, G. GM Plants Compared to the Baseline; A Whole Genome Sequencing Approach (CGM 2015-07). Available online: http://www.cogem.net/index.cfm/en/publications/ (accessed on 28 April 2016). 
12. Tayeh, N.; Aluome, C.; Falque, M.; Jacquin, F.; Klein, A.; Chauveau, A.; Berard, A.; Houtin, H.; Rond, C.; Kreplak, J.; et al. Development of two major resources for pea genomics: The GenoPea 13.2 K SNP Array and a high-density, high-resolution consensus genetic map. Plant J. 2015, 84, 1257-1273. [CrossRef] [PubMed]

13. Saxena, R.K.; Edwards, D.; Varshney, R.K. Structural variations in plant genomes. Brief. Funct. Genom. 2014, 13, 296-307. [CrossRef] [PubMed]

14. Kyndt, T.; Quispe, D.; Zhaic, H.; Jarret, R.L.; Ghislain, M.; Liuc, Q.; Gheysen, G.; Kreuze, J.F. The genome of cultivated sweetpotato contains functional Agrobacterium T-DNAs: An example of a naturally transgenic food crop. Proc. Natl. Acad. Sci. USA 2015, 112, 5844-5849. [CrossRef] [PubMed]

15. Haverkort, A.J.; Boonekamp, P.M.; Hutten, R.; Jacobsen, E.; Lotz, L.A.P.; Kessel, G.J.T.; Vossen, J.H.; Visser, R.G.F. Durable Late Blight Resistance in Potato Through Dynamic Varieties Obtained by Cisgenesis: Scientific and Societal Advances in the DuRPh Project. Potato Res. 2016, 59, 35-66. [CrossRef]

16. Haesaert, G.; Vossen, J.H.; Custers, R.; de Loose, M.; Haverkort, A.; Heremans, B.; Hutten, R.; Kessel, G.; Landschoot, S.; Van Droogenbroeck, B.; et al. Transformation of the potato variety Desiree with single or multiple resistance genes increases resistance to late blight under field conditions. Crop Prot. 2015, 77, 163-175. [CrossRef]

17. Organic Materials Review Institute. Available online: www.omri.org (accessed on 24 June 2016).

18. Haverkort, A.J.; Struik, P.C.; Visser, R.G.F.; Jacobsen, E. Applied biotechnology to combat late blight in potato caused by Phytophthora infestans. Potato Res. 2009, 52, 249-264. [CrossRef]

19. Cisgenesis. Available online: www.cisgenesis.com (accessed on 24 June 2016).

20. Vleeshouwers, V.G.A.A.; Raffaele, S.; Vossen, J.H.; Champouret, N.; Oliva, R.; Segretin, M.E.; Rietman, H.; Cano, L.M.; Lokossou, A.A.; Kessel, G.J.T.; et al. Understanding and exploiting late blight resistance in the age of effectors. Annu. Rev. Phytopathol. 2011, 49, 507-531. [CrossRef] [PubMed]

21. Zhu, S.; Ying, L.; Vossen, J.H.; Visser, R.G.F.; Jacobsen, E. Functional stacking of three resistance genes against Phytophthora infestans in potato. Transgenic Res. 2012, 21, 89-99. [CrossRef] [PubMed]

22. EFSA GMO Panel (EFSA Panel on Genetically Modified Organisms). Scientific opinion addressing the safety assessment of plants developed through cisgenesis and intragenesis. EFSA J. 2012. [CrossRef]

23. Friedman, M.; McDonald, G.M.; Filadelfi-Keszi, M. Potato Glycoalkaloids: Chemistry, Analysis, Safety, and Plant Physiology. Crit. Rev. Plant. Sci. 1997, 16, 55-132. [CrossRef]

24. McHughen, A. A critical assessment of regulatory triggers for products of biotechnology: Product vs. process. GM Crops Food 2016, 7, 125-158. [CrossRef] [PubMed]

25. Overview of Plant Incorporated Protectants. Available online: https://www.epa.gov/regulationbiotechnology-under-tsca-and-fifra/overview-plant-incorporated-protectants (accessed on 13 January 2017).

26. Miller, J.K.; Bradford, K.J. The regulatory bottleneck for biotech specialty crops. Nat. Biotechnol. 2010, 28, 1012-1014. [CrossRef] [PubMed]

27. Schiek, B.; Hareau, G.; Baguma, Y.; Medakker, A.; Douches, D.; Shotkoski, F.; Ghislain, M. Demystification of GM crop costs: Releasing late blight resistant potato varieties as public goods in developing countries. Int. J. Biotechnol. 2016, 14, 112-131. [CrossRef]

28. White, F.D.; Garfinkel, J.; Huffman, G.A.; Gordon, M.P.; Nester, E.W. Sequences homologous to Agrobacterium rhizogenes T-DNA in the genomes of uninfected plants. Nature 1983, 301, 348-350. [CrossRef]

29. Forsbach, A.; Schubert, D.; Lechtenberg, B.; Gils, M.; Schmidt, R. A comprehensive characterization of single-copy T-DNA insertions in the Arabidopsis thaliana genome. Plant Mol. Biol. 2003, 52, 161-176. [CrossRef] [PubMed]

30. Petitions for Determination of Nonregulated Status. Available online: https://www.aphis.usda.gov/aphis/ ourfocus/biotechnology/permits-notifications-petitions/petitions/petition-status (accessed on 13 January 2017).

31. US Public Law 114-216-July 29, 2016. National Bioengineered Food Disclosure Standard. Available online: https:/ / www.congress.gov/bill/114th-congress/senate-bill/764 (accessed on 17 November 2016).

32. Pure Himalayan Fine Grind Salt Pink, 5 Pounds. Available online: www.amazon.com/Salt-HimalayanChemicals-Non-gmo-Organic/dp/B007V8A34M (accessed on 24 June 2016).

33. New Breeding Techniques. Available online: www.easac.eu/fileadmin/PDF_s/reports_statements/Easac_ 14_NBT.pdf (accessed on 24 June 2016).

34. ACRE Advice: New Techniques Used in Plant Breeding. Available online: https://www.gov.uk/ government/uploads/system/uploads/attachment_data/file/239542/new-techniques-used-in-plantbreeding.pdf (accessed on 7 July 2016). 
35. Van Bueren, E.T.L.; Verhoog, H.; Tiemens-Hulscher, M.; Struik, P.C.; Haring, M.A. Organic agriculture requires process rather than product evaluation of novel breeding techniques. NJAS Wagen J. Life Sci. 2007, 54, 401-412. [CrossRef]

36. Van Bueren, E.T.L.; Struik, P.C.; Tiemens-Hulscher, M.; Jacobsen, E. Concepts of intrinsic value and integrity of plants in organic plant breeding and propagation. Crop Sci. 2003, 43, 1922-1929. [CrossRef]

37. Prakash, S.; Bhat, S.R.; Quiros, C.F.; Kirti, P.B.; Chopra, V.L. Brassica and Its Close Allies: Cytogenetics and Evolution. In Plant Breeding Reviews; Janick, J., Ed.; John Wiley \& Sons, Inc.: Hoboken, NJ, USA, 2009; Volume 31.

38. Gruber, K. Re-igniting the green revolution with wild crops. Nat. Plants 2016. [CrossRef] [PubMed]

39. Gruber, K. Giving fruit a nutritional boost. Nat. Plants 2016. [CrossRef] [PubMed]

40. Jones, J.T.; Furlanetto, C.; Kikuchi, T. Horizontal gene transfer from bacteria and fungi as a driving force in the evolution of plant parasitism in nematodes. Nematology 2005, 7, 641-646. [CrossRef]

41. Jacobsen, E.; Schouten, H.J. Cisgenesis strongly improves introgression breeding and induced translocation breeding of plants. Trends Biotechnol. 2007, 25, 219-223. [CrossRef] [PubMed]

42. Van Bueren, E.T.; Tiemens-Hulscher, M.; Struik, P.C. Cisgenesis Does Not Solve the Late Blight Problem of Organic Potato Production: Alternative Breeding Strategies. Potato Res. 2008, 51, 89-99. [CrossRef]

43. National Organic Program. Available online: www.ams.usda.gov/about-ams/programs-offices/nationalorganic-program (accessed on 17 November 2016).

44. Jinek, M.; Chylinski, K.; Fonfara, I.; Hauer, M.; Doudna, J.A.; Charpentier, E. A programmable Dual-RNA-guided DNA endonuclease in adaptive bacterial immunity. Science 2012, 337, 816-821. [CrossRef] [PubMed]

45. Sun, K.; Wolters, A.-M.A.; Loonen, A.E.H.M.; Huibers, R.P.; van der Vlugt, R.; Goverse, A.; Jacobsen, E.; Visser, R.G.F.; Bai, Y. Down-regulation of Arabidopsis DND1 orthologs in potato and tomato leads to broad-spectrum resistance to late blight and powdery mildew. Transgenic Res. 2016, 25, 123-138. [CrossRef] [PubMed]

46. CRISPR Hat Großes Potenzial. Available online: http://www.taz.de/Oekoforscher-ueber-neue-GentechMethode/!5290509/ (accessed on 17 January 2017). (In German)

(C) 2017 by the authors; licensee MDPI, Basel, Switzerland. This article is an open access article distributed under the terms and conditions of the Creative Commons Attribution (CC BY) license (http://creativecommons.org/licenses/by/4.0/). 